\title{
Atomic Spectroscopy S
}

\section{New Natural and Fused Quartz Reference Materials for Oxygen Isotope Microanalysis}

\author{
Guo-Qiang Tang, ${ }^{\text {a,b,c }}$ Yu Liu, ${ }^{\text {a,b }}$ Qiu-Li Li, ${ }^{\text {a,b,c }}$ Lian-Jun Feng, ${ }^{\text {a,b }}$ Gang-Jian Wei, ${ }^{\text {d }}$ Wen Su, ${ }^{\text {a,b }}$ Yang Li, ${ }^{\text {a,b }}$ \\ Guo-Hao Ren, ${ }^{\mathrm{e}}$ and Xian-Hua Li ${ }^{\mathrm{a}, \mathrm{b}, \mathrm{c}, *}$ \\ a State Key Laboratory of Lithospheric Evolution, Institute of Geology and Geophysics, Chinese Academy of Sciences, Beijing 100029, P.R. China \\ b Innovation Academy of Earth Science, Chinese Academy of Sciences, Beijing 100029, P.R. China \\ c College of Earth and Planetary Sciences, University of Chinese Academy of Sciences, Beijing 100049, P.R. China \\ d Guangzhou Institute of Geochemistry, Chinese Academy of Sciences, Guangzhou 510640, P.R. China \\ e Shanghai Institute of Ceramics, Chinese Academy of Sciences, Shanghai 201899, P.R. China
}

Received: 15 August 2020, Revised: 15 September 2020, Accepted: 15 September 2020, Available online: 19 September 2020.

DOI: 10.46770/AS.2020.05.002

ABSTRACT: Silicon dioxide $\left(\mathrm{SiO}_{2}\right)$ occurs as both crystallized quartz and amorphous quartz, and their oxygen isotope is widely used to trace the source of hydrothermal fluids, to reconstruct paleotemperature of oceans and to provide genetic constraints on petrogenetic studies. Precise and accurate oxygen isotope analysis, therefore, is fundamental for the application of oxygen isotope study. Secondary Ion Mass Spectrometry (SIMS) is capable of obtaining oxygen isotope information at micron levels, but precise and accurate SIMS isotopic microanalysis requires high quality reference materials to correct instrumental mass fractionation and to monitor data quality. In this study, we report two reference materials, a natural crystallized quartz (Qinghu-Qtz) from Qinghu quartz monzonite (Guangdong, P.R. China) and a fused amorphous quartz (Glass-Qtz). Multiple SIMS analyses suggest that both Qinghu-Qtz and Glass-Qtz are homogeneous in terms of oxygen isotope composition at ca. $20 \mu \mathrm{m}$ level, with a two-standard deviation of $0.50 \%$ o $(\mathrm{N}=1083)$ and $0.22 \%$ ( $\mathrm{N}=283)$, respectively. In comparison, the widely utilized NBS-28 quartz reference material, designed for bulk analysis, is less homogeneous at micro levels. The $\delta^{18}$ Ovsmow values of the two reference materials were obtained by conventional fluorination isotope ratio mass spectrometry (IRMS) and the

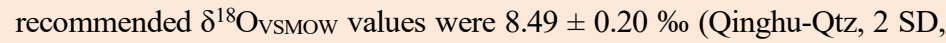
$\mathrm{N}=12$ ) and $1.68 \pm 0.08 \%$ (Glass-Qtz, $2 \mathrm{SD}, \mathrm{N}=10$ ).
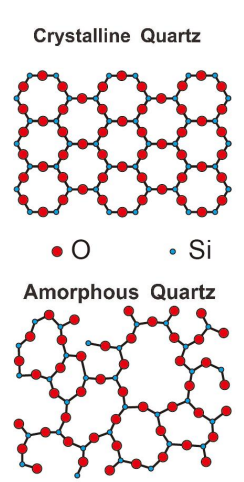
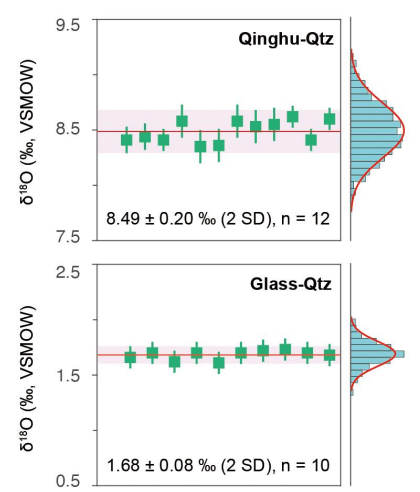

\section{INTRODUCTION}

Quartz is one of the most abundant minerals in the Earth's continental crust and is common in plutonic, sedimentary and metamorphic rock. ${ }^{1}$ The oxygen isotope of quartz is widely utilized in earth science research, such as for tracing the source of hydrothermal fluids, ${ }^{2-6}$ calculating oxygen isotope equilibrium temperatures $^{7-9}$ and reconstructing geological processes. ${ }^{10-12}$ The oxygen isotope composition of quartz is typically measured using either the conventional $\mathrm{CO}_{2}$ laser fluorination (LF) method with a gas-source isotope ratio mass spectrometer (IRMS) or a secondary ion mass spectrometer (SIMS), such as CAMECA
IMS 1270/1280/1280-HR/1300 and Sensitive High-Resolution Ion Micro Probe (SHRIMP). ${ }^{13-15}$ SIMS has the advantage of in situ isotope measurement with high spatial resolution down to micron levels and generally is the default choice of isotope microanalysis. However, accurate and precise microanalysis requires high quality reference materials to correct instrumental mass fractionation (IMF) due to the matrix effect ${ }^{16}$ and for quality control. At present, NBS-28 $\left(\delta^{18} \mathrm{OVSMOW}_{\mathrm{V}}=9.64 \pm 0.12 \%\right.$, $2 \mathrm{SD}),{ }^{17,18}$ UWQ-1 $\left(\delta^{18} \mathrm{OVSMOW}_{\mathrm{V}}=12.33 \pm 0.14 \%\right.$, $\left.2 \mathrm{SD}\right),{ }^{2,19}$ UNIL-Q1 $\left(\delta^{18} \mathrm{O}_{\text {vSMOw }}=9.8 \pm 0.12 \%, 2 \mathrm{SD}\right)^{20}$ and BGI-Q1 $\left(\delta^{18} \mathrm{OVSMOW}_{\text {v }}=7.7 \pm 0.22 \% \text {, } 2 \mathrm{SD}\right)^{20,21}$ are the mostly frequently 
used oxygen isotope reference materials for crystallized quartz measurements. NBS-28 is a well-established quartz oxygen isotope reference material designed for bulk analysis with quartz being separated from a sandstone. ${ }^{18}$ As demonstrated by the LF methods, it is fairly homogeneous in oxygen isotope composition at milligram level, and has served as a working reference material for in situ analysis, but it is not found to be homogeneous in oxygen isotope analysis at micrometer levels. UWQ-1 is an optical-grade vein quartz and has been used as a working reference material at the University of Wisconsin (USA).,13,19 UNIL-Q1 and BGI-Q1 are recently developed reference materials for SIMS oxygen isotope analysis which are milky quartz and smoky quartz, respectively. ${ }^{20}$ In addition to crystallized quartz, silicon dioxide also occurs as uncrystallized materials, such as the chemically precipitated chert and cryptocrystalline quartz in banded iron formations (BIFs). Here we refer to these uncrystallized quartz materials as amorphous quartz, for which no reference material has been available and thus hinders SIMS oxygen microanalysis.

In this study, we investigate the homogeneity of the oxygen isotope compositions of NBS-28 quartz reference material, a natural crystallized quartz (Qinghu-Qtz), obtained from Qinghu quartz monzonite, southeastern China, and a fused quartz (GlassQtz), and evaluate their potential as reference materials for microanalysis.

\section{DESCRIPTION OF SAMPLES}

Qinghu-Qtz. Qinghu-Qtz was obtained from the Qinghu quartz monzonite located near the border of Guangxi and Guangdong provinces in South China. ${ }^{22}$ Integrated geochemical and Sr-Nd$\mathrm{O}-\mathrm{Hf}$ isotopic analysis indicates that the Qinghu monzonite was derived from the lithospheric mantle without appreciable crustal contamination. $^{20-21}$ Detailed information on the pluton can be found in Li et al. (2009). ${ }^{22}$ Zircon from the Qinghu pluton has been successfully developed as reference material for $\mathrm{U}-\mathrm{Pb}$ dating, hafnium and oxygen isotope microanalysis. ${ }^{23} \mathrm{Ca} .20 \mathrm{~g}$ quartz grains were separated from a rock specimen collected at a quarry $\left(22^{\circ} 01^{\prime} 38.7^{\prime \prime} \mathrm{N}, 110^{\circ} 21^{\prime} 12.3^{\prime \prime} \mathrm{E}\right)$ near the town of Qinghu. The Qinghu-Qtz is mostly anhedral with dimensions of tens to hundreds of micrometers.

Glass-Qtz. Glass-Qtz is a fused quartz glass produced in the Jingshi Company (Taicang city, Jiangsu province, P.R. China) by fusing high-purity quartz sand from the Donghai county of China. The fusing was carried out at about $1700{ }^{\circ} \mathrm{C}$ and $0.1-10 \mathrm{~Pa}$ vacuum environment. After annealing in vacuum, a colorless transparent and stress-free fused quartz glass plate was obtained. A piece of fused quartz glass plate with rectangular shape and a weight of $\sim 24.4 \mathrm{~g}$ was cut and investigated in this study (GlassQtz). The plate was sliced and crushed into shards with dimensions of hundreds of micrometers for oxygen isotope analysis.

\section{ANALYTICAL METHODS}

Laser-Raman is used to obtain structural information of the samples. SIMS is used to test the homogeneity of the oxygen isotopic composition, and the recommended oxygen isotope values are determined by LF and the furnace fluorination method using an Isotope Ratio Mass Spectrometer (IRMS). ${ }^{18} \mathrm{O} /{ }^{16} \mathrm{O}$ ratios are normalized using the Vienna Standard Mean Ocean Water (VSMOW, $\left.{ }^{18} \mathrm{O} /{ }^{16} \mathrm{O}=0.00200520\right)^{24}$ and expressed in conventional $\delta$-notation (\%o).

Laser-Raman. Laser-Raman spectroscopy analyses were performed using a confocal Raman Microscope alpha 300R, manufactured by WITec GmbH (Ulm, Germany), located at the Institute of Geology and Geophysics, Chinese Academy of Sciences (IGG-CAS). We used a wave-length of $532 \mathrm{~nm}$ and a spot diameter of $1 \mu \mathrm{m}$ for Laser-Raman scanning. A $50 \times(\mathrm{NA}=$ $0.55)$ ZEISS objective lens was used for excitation and detection, and the Rayleigh light was rejected by an edge filter. A 300 grooves/mm grating was used to disperse the light with the spectral resolution of $4.5 \mathrm{~cm}^{-1}$. The measurement range was 10 $4000 \mathrm{~cm}^{-1}$. The laser with a power of $8 \mathrm{~mW}$ was focused on the sample, the acquisition time was $1 \mathrm{~s}$. The confocal Raman image was measured using $340 \mu \mathrm{m} \times 200 \mu \mathrm{m}$, and the acquisition time of each spectrum was $1 \mathrm{~s}$. The acquired image was visualized using WITec Project and WITec Plus Software.

SIMS. The Qinghu-Qtz crystals and Glass-Qtz shards, along with NBS-28 quartz grains, were mounted in epoxy resin and polished for SIMS analysis to evaluate their homogeneity of oxygen isotope at micron levels. SIMS analysis was conducted using CAMECA IMS 1280 in IGG-CAS. Specifically, QinghuQtz and NBS-28 were utilized as working references in IGG$\mathrm{CAS}$ in the past decade, as such considerably more analyses than for Glass-Qtz were conducted. Cesium ions were used as the primary beam to bombard the sample grains with $20 \mathrm{KeV}$ energy. The primary beam was focused in Gaussian mode with a diameter of $\sim 10 \times 15 \mu \mathrm{m}^{2}$, and the intensity used was $1.0-7.0 \mathrm{nA}$ during the year of $2013-2020$. The primary beam was used in raster mode with a size of $\sim 10 \mu \mathrm{m}$. A normal incidence electron gun was used to deliver the electrons to sample mount surface to compensate the charging effect. The magnification power was configured to ca. 133 for the transfer lens to project the sample surface to field aperture. The width of field aperture was $6 \mathrm{~mm} \times 6 \mathrm{~mm}$. The energy slit width was $40 \mathrm{eV}$. From the year 2013 to 2019 , the entrance slit with a width of $\sim 120 \mu \mathrm{m}$ was used, and the mass resolution constrained by a $500 \mu \mathrm{m}$ width exit slit on the multicollector system was 2400 ( $50 \%$ peak width). The signals of ${ }^{16} \mathrm{O}$ and ${ }^{18} \mathrm{O}$ were simultaneously accepted by two Faraday cups with $10^{10} \mathrm{Ohms}$ and $10^{11} \mathrm{Ohms}$ resistors. The intensity of the ${ }^{16} \mathrm{O}$ signal ranged from ca. $1.0 \times 10^{9} \mathrm{cps}$ (counts per second) to ca. $4.0 \times 10^{9} \mathrm{cps}$.

The instrument configuration was upgraded in June 2020. In brief, customized exit slits with a width of $700 \mu \mathrm{m}$ and $1200 \mu \mathrm{m}$ 


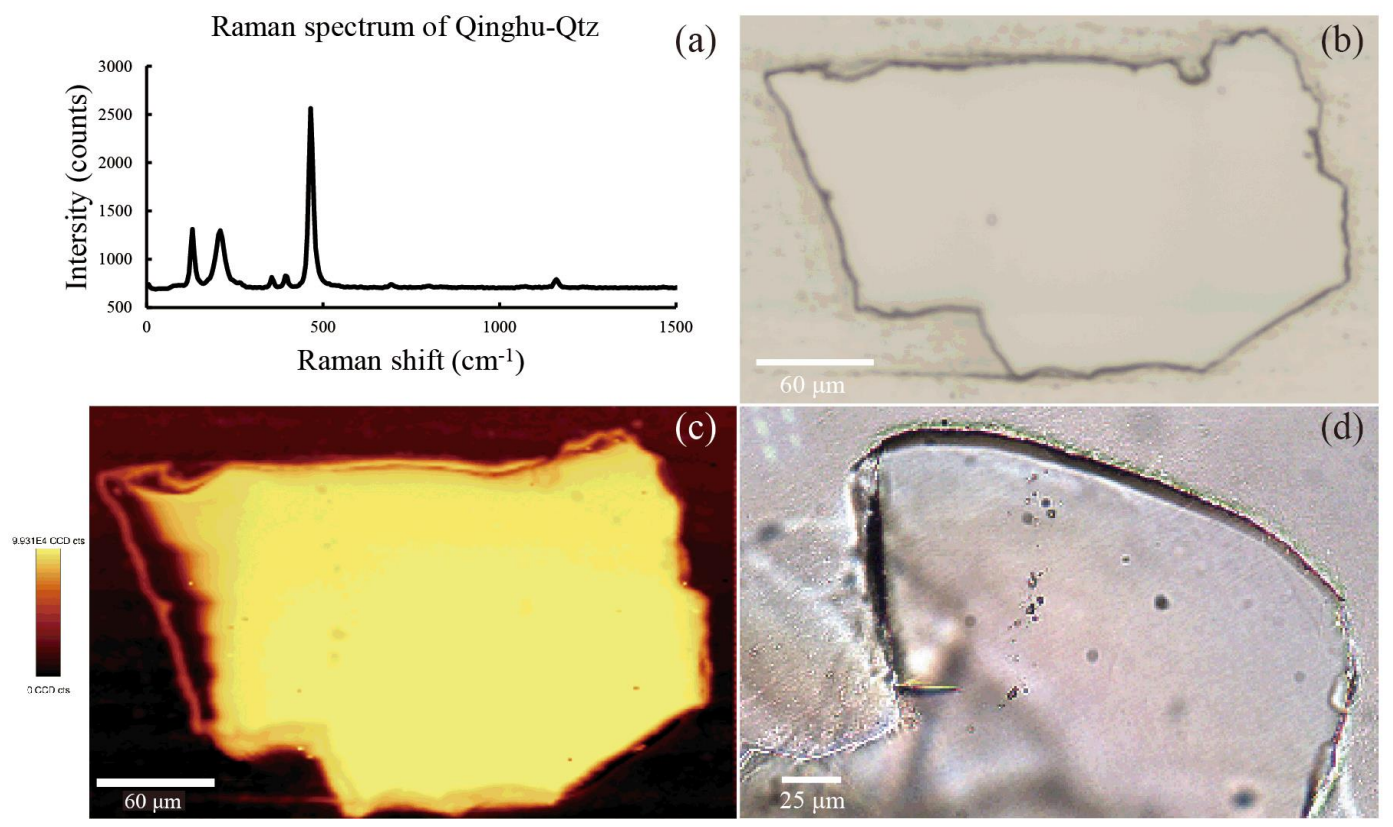

Fig. 1 (a) Typical Raman spectrum of Qinghu-Qtz; (b) Reflected light image of a Qinghu-Qtz grain; (c) Raman spectral image of the same Qinghu-Qtz grain in (b); (d) Small gas-liquid inclusions in Qinghu-Qtz.

were used on two Faraday collectors to measure ${ }^{16} \mathrm{O}$ and ${ }^{18} \mathrm{O}$, respectively, and the corresponding resistors were $10^{9}$ and $10^{12}$ Ohms. The width of the entrance slit was $\sim 200 \mu \mathrm{m}$. Benefiting from the wider entrance and exit slits, the efficiency of ion transmission was improved by $\sim 15 \%$. In addition, the optimization of high value resistors used for the Faraday cups were helpful to increase the internal precision of the ${ }^{18} \mathrm{O} /{ }^{16} \mathrm{O}$ isotope ratios. Glass-Qtz was analyzed after the instrumental upgrade, and the intensity of the ${ }^{16} \mathrm{O}$ signal ranged from ca. $4.5 \times$ $10^{9}$ cps to ca. $8.4 \times 10^{9} \mathrm{cps}$.

IRMS. The $\delta^{18} \mathrm{O}$ values of Qinghu-Qtz and Glass-Qtz were determined using the conventional fluorination method in four laboratories: the Stable Isotope Laboratory of Department of Geoscience, the University of Wisconsin, USA; the Institute of Earth Sciences (IES), Academia Sinica, Taipei; the Guangzhou Institute of Geochemistry, Chinese Academy of Sciences (GIGCAS); and the Stable Isotope Laboratory in IGG-CAS. The Qinghu-Qtz results from IGG-CAS were obtained by the furnace fluorination method and all other results were obtained by using the LF method. UWG-2 garnet, ${ }^{25}$ Chinese national reference material GBW04409, and 04BXL07 garnet $^{26}$ were analyzed during the course of this study for quality control. The detailed analytical condition can be found in previous studies. ${ }^{27-29}$ For the LF method, 1-2 mg sample materials were used for each analysis. The samples were reacted with purified $\mathrm{BrF}_{5}$ reagent in the laser chamber to liberate oxygen. For the furnace fluorination method, the samples were fluorinated in nickel reaction vessels, and each analysis consumed ca. $6 \mathrm{mg}$ of materials. The samples were loaded under a positive pressure of pure $\mathrm{N}_{2}$ to prevent adsorption of atmospheric moisture in the nickel reaction vessel. After the initial overnight pumping and a 10-minute room temperature pre-

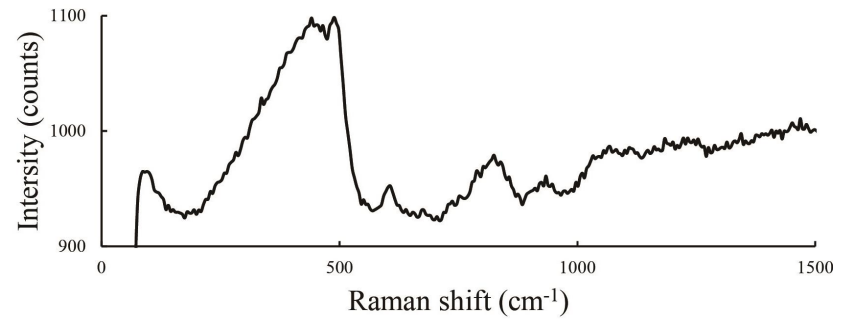

Fig. 2 Raman spectrum of Glass-Qtz.

fluorination with $\mathrm{BrF}_{5}$, the vessel was evacuated and again charged with an aliquot of $\mathrm{BrF}_{5}$. The nickel reaction vessel was heated to $750{ }^{\circ} \mathrm{C}$ with a resistance furnace for 4 hours. The gases generated were purified through a series of cryogenic traps which were chilled by liquid nitrogen. The purified oxygen gas was analyzed by IRMS.

\section{RESULTS AND DISCUSSION}

Laser-Raman results. A Raman spectrum was obtained for a representative Qinghu-Qtz grain in Fig. 1a, which is very typical for crystallized quartz. A reflected light image and Raman spectral image for the grain are shown in Fig. 1b and Fig. 1c, respectively. As shown in Fig. 1d, except for occasionally observed small gas-liquid inclusions, the Qinghu-Qtz grains are very pure and clean, thus are suitable for SIMS reference material development.

The Raman spectrum of the Glass-Qtz is characterized by a broad band centering at $440 \mathrm{~cm}^{-1}$, with two smaller bands at $490 \mathrm{~cm}^{-1}$ and $606 \mathrm{~cm}^{-1}$ (Fig. 2), which is diagnostic for fused quartz. ${ }^{30-32}$ 

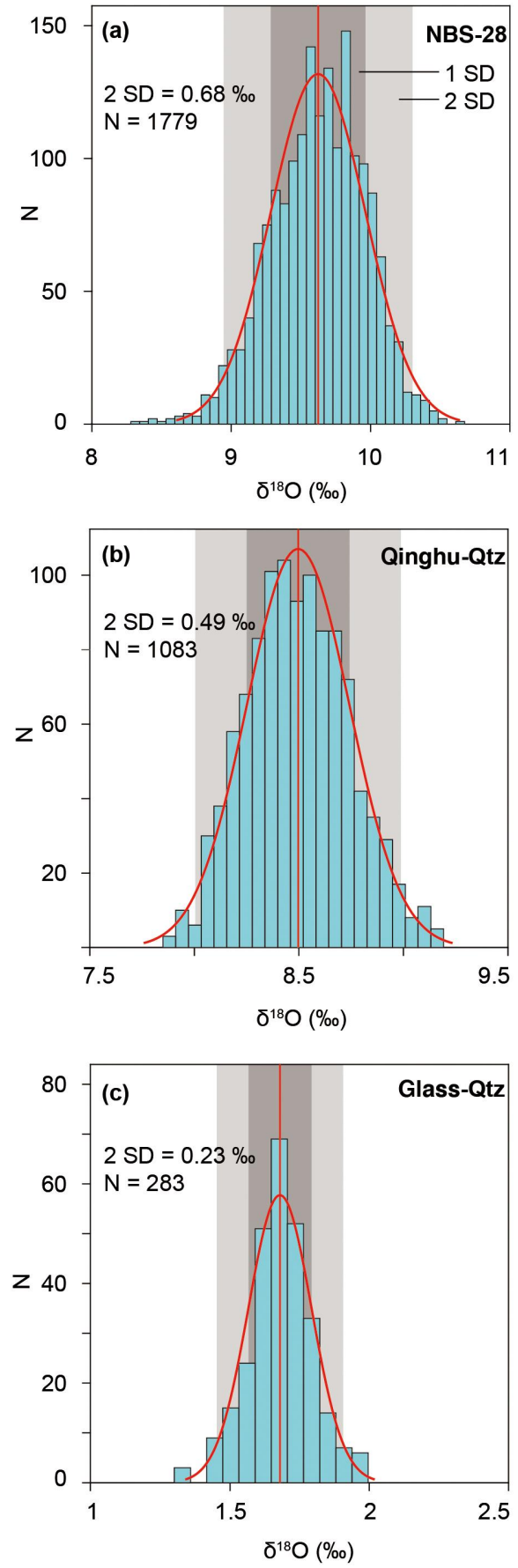

Fig. 3 Probabilistic histograms of SIMS results for NBS-28, Qinghu-Qtz and Glass-Qtz.

SIMS results. The SIMS oxygen isotope data of NBS-28 quartz, Qinghu-Qtz and Glass-Qtz for the homogenization test are presented in Appendix S1 and visualized in Fig. 3 as probabilistic histograms. During the year of 2013-2020, a total of 1779 and 1083 SIMS oxygen isotope measurements were conducted on NBS-28 and Qinghu-Qtz, respectively, as working reference materials. The data were collected during 113 sessions. When pooled together, the $2 \mathrm{SD}$ for Qinghu-Qtz was $0.50 \%$

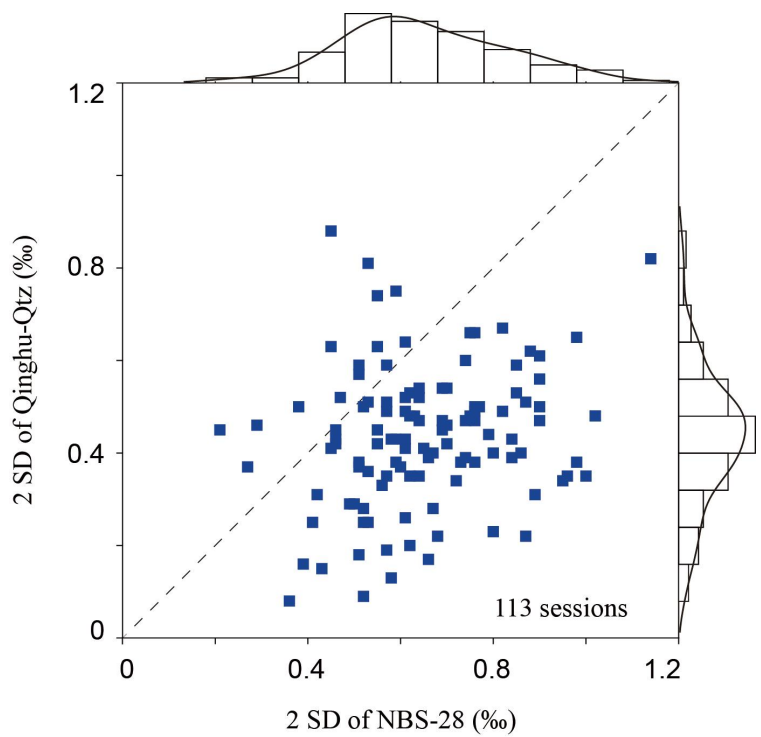

Fig. 4 SDs comparision for NBS-28 and Qinghu-Qtz from multiple sessions. For most sessions, 2 SD of NBS-28 are larger than $0.5 \%$, while 2 SD of Qinghu-Qtz are lower than $0.5 \%$.
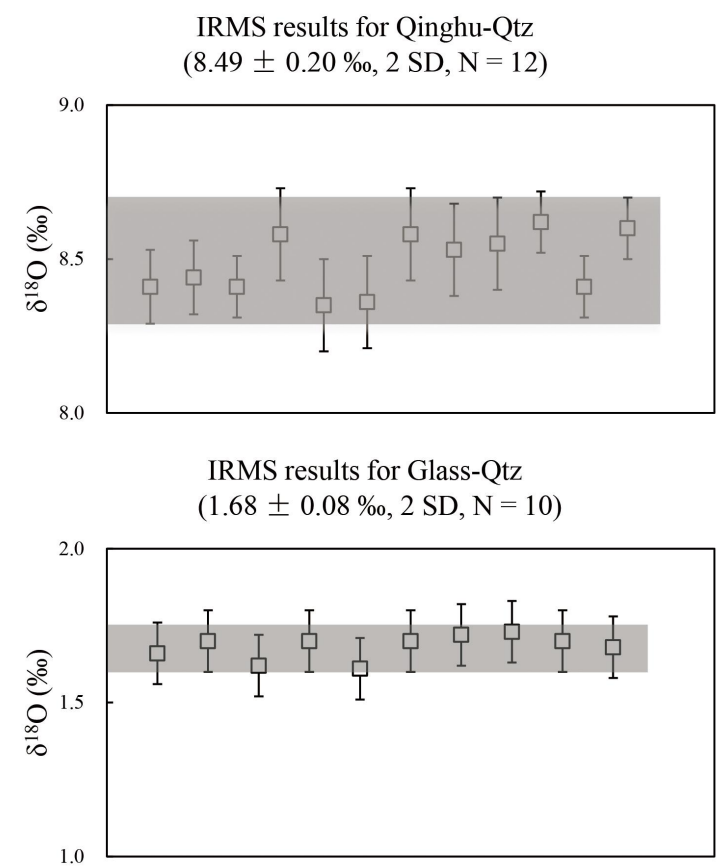

Fig. 5 IRMS results for Qinghu-Qtz and Glass-Qtz.

$(\mathrm{N}=1083)$, and the 2 SD for NBS-28 was $0.68 \%$ o $(\mathrm{N}=1779)$. We further used the 2 SDs of Qinghu-Qtz and NBS-28 from each session to evaluate their homogeneity in terms of oxygen isotope composition. As shown in Fig. 4, Qinghu-Qtz is generally more homogeneous than NBS-28, with a mean 2 SD of $0.44 \%$ and $0.65 \%$, respectively.

A total of 283 SIMS oxygen isotope measurements were conducted on Glass-Qtz, and the corresponding 2 SD was $0.22 \%$ $(\mathrm{N}=283)$. 
Table 1. IRMS Oxygen Isotope Results for Qinghu-Qtz and Glass-Qtz

\begin{tabular}{|c|c|c|c|}
\hline Sample & $\delta^{18} \mathrm{O}(\%)$ & 2 SD (\%) & Lab. $^{*}$ \\
\hline \multirow{12}{*}{ Qinghu-Qtz } & 8.41 & 0.12 & 1 \\
\hline & 8.44 & 0.12 & 1 \\
\hline & 8.41 & 0.10 & 2 \\
\hline & 8.58 & 0.15 & 3 \\
\hline & 8.35 & 0.15 & 3 \\
\hline & 8.36 & 0.15 & 3 \\
\hline & 8.58 & 0.15 & 3 \\
\hline & 8.53 & 0.15 & 3 \\
\hline & 8.55 & 0.15 & 3 \\
\hline & 8.62 & 0.10 & 4 \\
\hline & 8.41 & 0.10 & 4 \\
\hline & 8.60 & 0.10 & 4 \\
\hline \multirow[t]{4}{*}{ Mean } & & $.20 \%$ (2 SI & \\
\hline & 1.66 & 0.10 & 4 \\
\hline & 1.70 & 0.10 & 4 \\
\hline & 1.62 & 0.10 & 4 \\
\hline \multirow{7}{*}{ Glass-Qtz } & 1.70 & 0.10 & 4 \\
\hline & 1.61 & 0.10 & 4 \\
\hline & 1.70 & 0.10 & 4 \\
\hline & 1.72 & 0.10 & 4 \\
\hline & 1.73 & 0.10 & 4 \\
\hline & 1.70 & 0.10 & 4 \\
\hline & 1.68 & 0.10 & 4 \\
\hline Mean & & $.08 \%$ (2 SI & \\
\hline
\end{tabular}

"Lab. 1: Stable Isotope Laboratory of Department of Geoscience, University of Wisconsin; Lab. 2: Stable Isotope Laboratory at Institute of Earth Sciences, Academia Sinica; Lab. 3: Stable Isotope Laboratory at Guangzhou Institute of Geochemistry, Chinese Academy of Sciences; Lab. 4: Stable Isotope Laboratory at Institute of Geology and Geophysics, Chinese Academy of Sciences. The reproducibility of IRMS were monitored through multiple analyses of standards and are shown as $2 \mathrm{SD}$.

IRMS results. The oxygen isotopes of Qinghu-Qtz and GlassQtz, determined by IRMS, are plotted in Fig. 5 with the data listed in Table 1. The average $\delta^{18} \mathrm{O}$ of Qinghu-Qtz and Glass-Qtz was $8.49 \pm 0.20 \%$ ( $2 \mathrm{SD}, \mathrm{n}=12)$ and $1.68 \pm 0.08 \%$ ( $2 \mathrm{SD}$, $\mathrm{n}=10$ ), respectively.

\section{CONCLUSIONS}

Qinghu-Qtz is exceptionally pure and clean, except for the presence of micro fluid inclusions (Fig. 1d), which do not impact SIMS oxygen isotope analysis. Our SIMS results of Qinghu-Qtz ( $2 \mathrm{SD}=0.50 \%, \mathrm{~N}=1083$ ) during the past decade suggest that the sample is homogeneous in terms of oxygen isotope composition. As such, it meets the criteria for use as a reference material for SIMS oxygen isotope analysis.

For Glass-Qtz, the limited variation of $\delta^{18} \mathrm{O}(2 \mathrm{SD}=0.22 \%$, $\mathrm{N}=283$ ) during SIMS analysis indicates that the fused quartz has extremely homogeneous oxygen isotope composition. In this regard, Glass-Qtz is also suitable as SIMS reference material for amorphous quartz samples, such as chert and amorphous quartz in BIFs.
Multiple sessions of SIMS analysis for Qinghu-Qtz and NBS28 permit further evaluation of their homogeneity of oxygen isotopic composition in variable instrumental conditions (Figure 4). For the 113 sessions conducted in the last decade, the $2 \mathrm{SD}$ of NBS-28 from 98 sessions are larger than that of Qinghu-Qtz, which indicates that it is less homogeneous in oxygen isotope composition. This result is not surprising since NBS-28 was separated from a sandstone and originally designed for bulk analysis. Although NBS-28 is the most commonly used reference material for oxygen and silicon isotope microanalysis, our results suggest that NBS-28 is less ideal as a reference material for SIMS oxygen isotope microanalysis, as similar results have been shown in SIMS silicon isotope microanalysis. ${ }^{33,34}$

In conclusion, Qinghu-Qtz and Glass-Qtz are homogeneous in terms of oxygen isotope composition at micro-levels and are suitable to be used as reference materials for SIMS microanalysis. In comparison, NBS-28 is found to be less suitalbe. The recommended $\delta^{18} \mathrm{O}$ values of Qinghu-Qtz and Glass-Qtz were $8.49 \pm 0.20 \%$ ( $2 \mathrm{SD}$ ) and $1.68 \pm 0.08 \%$ ( $2 \mathrm{SD}$ ) as measured by IRMS. Both materials are available on request sent to the corresponding author.

\section{ASSOCIATED CONTENT}

Please contact the corresponding author for Supporting Information. Appendix S1, SIMS oxygen isotope data of NBS28 quartz, Qinghu-Qtz and Glass-Qtz for homogenization test.

\section{AUTHOR INFORMATION}

\section{Corresponding Author}

*X.-H. Li

Email address: lixh@gig.ac.cn

\section{Notes}

The authors declare no competing financial interest.

\section{ACKNOWLEDGMENTS}

We appreciate the assistance of John Valley and Tzen-Fu Yui for IRMS analysis; Jiao Li for SIMS analysis; Xiao-Guang Li for Raman analysis and Hong-Xia Ma for sample preparation. This work was financially supported by the National Key R\&D Program of China (2018YFA0702600), Institute of Geology and Geophysics, Chinese Academy of Sciences (IGGCAS-201901), and the State Key Laboratory of Lithospheric Evolution (Z201705 and K201706). 


\section{REFERENCES}

1. J. Götze, Mineral. Mag., 2009, 73, 645-671. https://doi.org/10.1180/minmag.2009.073.4.645

2. C. M. Graham, J. W. Walley, and B. L. Winter, Geochim. Cosmochim. Acta., 1996, 60, 5101-5116. https://doi.org/10.1016/S0016-7037(96)00286-4

3. J. Harwood, A. C. Aplin, C. I. Fialips, J. E. Iliffe, R. Kozdon, T. Ushikubo, and J. W. Valley, J. Sediment. Res., 2013, 83, 522-530. http://dx.doi.org/10.2110/jsr.2013.29

4. A. M. Marchand, C. I. Macaulay, R. S. Haszeldine, and A. E. Fallick, Chem. Geol., 2002, 191, 285-304. http://dx.doi.org/10.1016/S0009-2541(02)00137-7

5. J. Schieber, D. Krinsley, and L. Riciputi, Nature, 2000, 406, 981-985. http://dx.doi.org/10.1038/35023143

6. L. B. Williams, R. L. Hervig, K. Bjørlykke, Geochim. Cosmochim. Acta., 1997, 61, 2529-2538. http://dx.doi.org/10.1016/S0016-7037(97)00111-7

7. J. W. Valley, I. N. Bindeman, and W. H. Peck, Geochim. Cosmochim. Acta., 2003, 67, 3257-3266. http://dx.doi.org/10.1016/S0016-7037(03)00090-5

8. R. J. Quinn, K. Kitajima, D. Nakashima, M. J. Spicuzza, and J. W. Valley, J. Metamorphic Geol., 2017, 35, 231-252. http://dx.doi.org/10.1111/jmg.12230

9. Z. D. Sharp and D. L. Kirschner, Geochim. Cosmochim. Acta., 1994, 58, 4491-4501. http://dx.doi.org/10.1016/0016-7037(94)90350-6

10. M. M. Allan and B. W. Yardley, Chem. Geol., 2007, 240, 343-360. http://dx.doi.org/ 10.1016/j.chemgeo.2007.03.004

11. S. K. Appleby, M. R. Gillespie, C. M. Graham, R. W. Hinton, G. J. Oliver, and N. M. Kelly, Contrib. Mineral. Petr., 2010, 160, 115-132. http://dx.doi.org/10.1007/s00410-009-0469-3

12. B. I. Kleine, A. Stefansson, S. A. Halldórsson, M. J. Whitehouse, and K. Jónasson, Geochem. Perspect. Let., 2018, 7, 5-11. http://dx.doi.org/10.7185/geochemlet.1811

13. D. Elsenheimer and J. W. Valley, Geochim. Cosmochim. Acta., 1993, 57, 3669-3676. http://dx.doi.org/10.1016/S0016-7037(03)00090-5

14. R. B. Ickert, J. Hiess, I. S. Williams, P. Holden, T. R. Ireland, P. Lanc, N. Schram, J. J. Foster, and S. W. Clement, Chem. Geol., 2008, 257, 114-128. http://dx.doi.org/10.1016/j.chemgeo.2008.08.024

15. G.-Q. Tang, X.-H. Li, Q.-L. Li, Y. Liu, X.-X. Ling, and Q.-Z. Yin, J. Anal. At. Spectrom., 2015, 30, 950-956. http://dx.doi.org/10.1039/C4JA00458B

16. J. M. Eiler, C. Graham, and J. W. Valley, Chem. Geol., 1997, 138, 221-244. http://dx.doi.org/10.1016/S0009-2541(97)00015-6

17. T. B. Coplen, C. Kendall, and J. Hopple, Nature, 1983, 302, 236-238 http://dx.doi.org/10.1038/302236a0
18. R. Gonfiantini, W. Stichler, and K. Rozanski, Standards and intercomparison materials distributed by the International Atomic Energy Agency for stable isotope measurements, 1995.

19. J. L. Kelly, B. Fu, N. T. Kita, and J. W. Valley, Geochim. Cosmochim. Acta., 2007, 71, 3812-3832. http://dx.doi.org/10.1016/j.gca.2007.05.014

20. S. Seitz, L. P. Baumgartner, A. S. Bouvier, B. Putlitz, and T. Vennemann, Geostand. Geoanal. Res., 2017, 41, 69-75. http://dx.doi.org/10.1111/ggr.12133

21. A. Audétat, D. Garbe-Schönberg, A. Kronz, T. Pettke, B. Rusk, J. J. Donovan, and H. A. Lowers, Geostand. Geoanal. Res., 2015, 39, 171-184. http://dx.doi.org/10.1111/j.1751-908X.2014.00309.x

22. X.-H. Li, W.-X. Li, X.-C. Wang, Q.-L. Li, Y. Liu, and G.-Q. Tang, Sci. China Ser. D., 2009, 52, 1262-1278. http://dx.doi.org/10.1007/s11430-009-0117-9

23. X.-H. Li, G.-Q, Tang, B. Gong, Y.-H. Yang, K.-J. Hou, Z.-C. Hu, Q.-L. Li, Y. Liu, and W.-X. Li, Chin. Sci. Bull., 2013, 58, 4647-4654. http://dx.doi.org/10.1007/s11434-013-5932-x

24. P. Baertschi, Earth Planet. Sci. Lett., 1976, 31, 341-344. http://dx.doi.org/10.1016/0012-821x(76)90115-1

25. J. W. Valley, N. Kitchen, M. J. Kohn, C. R. Niendorf, M. J. Spicuzza, Geochim. Cosmochim. Acta., 1995, 59, 5223-5231. http://dx.doi.org/10.1016/0016-7037(95)00386-X

26. B. Gong, Y.-F. Zheng, and R.-X. Chen, Phys. Chem. Miner., 2007, 34, 687-698. http://dx.doi.org/10.1007/s00269-007-0184-4

27. M. Spicuzza, J. Valley, M. Kohn, J. Girard, and A. Fouillac, Chem. Geol., 1998, 144, 195-203. http://dx.doi.org/10.1016/s0009-2541(97)00131-9

28. Y.-F. Zheng, Z.-R. Wang, S.-G. Li, and Z.-F. Zhao, Geochim. Cosmochim. Acta., 2002, 66, 625-634. http://dx.doi.org/10.1016/S0016-7037(01)00801-8

29. X. Liu, W.-F. Deng, J.-X. Wei, and G.-J. Wei, Bull. Mineral. Petrol. Geochemistry, 2016, 35, 448-453. http://dx.doi.org/10.3969/j.issn.1007-2802.2016.03.006

30. S. Bruns, T. Uesbeck, S. Fuhrmann, M. T. Aymerich, L. Wondraczek, D. de Ligny, and K. Durst, J. Am. Ceram. Soc., 2020, 103, 3076-3088. http://dx.doi.org/10.1111/jace.17024

31. J. W. Chan, T. Huser, S. Risbud, and D. Krol, Opt. lett., 2001, 26, 1726-1728. http://dx.doi.org/10.1364/OL.26.001726

32. A. Pasquarello and R. Car, Phys. Rev. Lett., 1998, 80, 5145-5147. http://dx.doi.org/10.1103/PhysRevLett.80.5145

33. P. R. Heck, J. M. Huberty, N. T. Kita, T. Ushikubo, R. Kozdon, and J. W. Valley, Geochim. Cosmochim. Acta., 2011, 75, 5879-5891. http://dx.doi.org/10.1016/j.gca.2011.07.023

34. Y. Liu, X.-H. Li, G.-Q. Tang, Q.-L. Li, X.-C. Liu, H.-M. Yu, and F. Huang, J. Anal. At. Spectrom., 2019, 34, 906-914. http://dx.doi.org/10.1039/C8JA00431E 